\title{
Uncertainty analysis of rainfall depth duration frequency curves using the bootstrap resampling technique
}

\author{
Jing Lin NG ${ }^{1, *}$, Samsuzana Abd Aziz ${ }^{2}$, Yuk Feng Huang ${ }^{3}$, Majid Mirzaei ${ }^{4}$, \\ AimRUn WAYAYOK ${ }^{2}$ and M K ROWSHON ${ }^{2}$ \\ ${ }^{1}$ Department of Civil Engineering, Faculty of Engineering, Technology $\&$ Built Environment, UCSI University, \\ Kuala Lumpur, Malaysia. \\ ${ }^{2}$ Department of Biological and Agricultural Engineering, Universiti Putra Malaysia, Selangor, Malaysia. \\ ${ }^{3}$ Department of Civil Engineering, Lee Kong Chian Faculty of Engineering and Science, Universiti Tunku Abdul \\ Rahman, Selangor, Malaysia. \\ ${ }^{4}$ Department of Civil Engineering, Faculty of Engineering, University of Malaya, Kuala Lumpur, Malaysia. \\ *Corresponding author.e-mail: ngjl@ucsiuniversity.edu.my
}

MS received 26 March 2017; revised 28 May 2018; accepted 25 December 2018; published online 8 May 2019

Rainfall depth duration frequency (DDF) curves are used extensively in many engineering designs. However, due to the sampling error and the uncertainty associated with the parameter estimation process, the DDF curves are subjected to parameter uncertainty. In this study, an evaluation of the uncertainty of the DDF curves in the Kelantan river basin was performed using the bootstrap resampling method. Annual maximum rainfall series for durations of 24, 48, 72, 96 and $120 \mathrm{~h}$ were derived from the stochastic rainfall model outputs and fitted to the generalised extreme value (GEV) distribution. The bootstrap samples were generated by resampling with replacement from the annual maximum rainfall series. The relationships that describe the GEV parameters as a function of duration were used to establish the DDF curves. The 95\% confidence intervals were used as an indicator to quantify the uncertainty in the DDF curves. The bootstrap distribution of the rainfall depth quantiles was represented by a normal probability density function. The results showed that uncertainty increased with the return period and there was significant uncertainty in the DDF curves. The suggested procedure is expected to contribute to endeavours in obtaining reliable DDF curves, where the uncertainty features are assessed.

Keywords. Depth duration frequency curves; uncertainty; bootstrap resampling; generalised extreme value distribution.

\section{Introduction}

Rainfall depth duration frequency (DDF) curves are graphical representations of the rainfall depths at a given duration having desired probabilities of exceedance or return period. They are particularly needed to model the extreme rainfall characteristics for hydrological and engineering applications, such as the design of sediment control structures, management of storm water facilities, risk analysis for flood hazards and the operations for urban drainage works (Brath et al. 2003; Jiang and Tung 2015; Sarhadi and Soulis 2017). This is especially true in Malaysia, which experiences extreme rainfall events (flash flood and monsoon flood) nearly every year, resulting in high economic losses, significant damages to property, degradation of water quality and loss of lives. However, the 
quantification of uncertainty associated with the DDF curves is often neglected or simply disregarded. This may affect the reliability of the hydrological modelling and leads to significant errors that may affect the decisions drawn from the research analysis. Therefore, it is important to assess and incorporate the uncertainty features when deriving the rainfall DDF relationships to obtain reliable estimations of extreme rainfall.

In general, the rainfall DDF curves are constructed based on extreme rainfall series at the location of interest for various durations. The typical steps involved are as follows: (i) fitting of the probability distribution function to the annual maximum rainfall series for a specific duration; (ii) estimating the quantile function of extreme rainfall for each duration with the corresponding return period and (iii) deriving rainfall DDF relationships between the rainfall depth and duration. Previously, the Gumbel distribution has been widely used to fit and describe the characteristics of annual maximum rainfall (Wotling et al. 2000; Borga et al. 2005; Nadarajah and Choi 2007). However, several studies have shown that the Gumbel distribution tends to underestimate the extreme rainfall quantiles and extreme events like floods appear to have heavier tails than the Gumbel distribution (Coles et al. 2003; Malamud and Turcotte 2006; Sisson et al. 2006; Papalexiou and Koutsoyiannis 2013). This may consequently lead to the inaccurate estimation of hydrological risk, particularly for the design of hydraulic structures or water resource projects that involve high return periods. Alternatively, the generalised extreme value (GEV) distribution is used as a consistent probabilistic model, where the additional parameter can describe better the upper tail of the extreme rainfall. For this reason, GEV distribution was applied in this study. GEV distribution has been applied in several regions to model the rainfall extremes and shown to be the appropriate distribution to model the behaviour of the extreme events, such as in Malaysia (Zalina et al. 2002), Korea (Nadarajah and Choi 2007), India (Guhathakurta et al. 2011), Canada (Burn 2014), Iran (Mirzaei et al. 2015) and China (Yin et al. 2016).

The evaluation of uncertainty is often overlooked for the typical estimation of the DDF curves. The main limitation of the typical DDF procedure is that the parameter uncertainty is not determined. In hydrological modelling, uncertainty is important to provide information on the hydrological models for future risk assessments. The bootstrap resampling approach has been adopted for uncertainty assessment in hydrology due to its simplicity and versatility. Overeem et al. (2008) assessed the uncertainty associated with the DDF curves by using the bootstrap method and obtained the uncertainty bands and the bootstrap distribution of uncertainty. Hailegeorgis et al. (2013) utilised the bootstrap method to analyse the sampling uncertainty associated with the quantile estimation of extreme rainfall events in Norway. The rainfall samples were drawn with replacement from original rainfall series and the confidence intervals were derived from the resamples. The confidence bounds of the rainfall quantiles showed that the uncertainty was high in the estimates. Similar findings were reported by Mirzaei et al. (2015) who assessed the uncertainty associated with the DDF curves in Iran by using the bootstrap method and calculated the confidence bands of the DDF curves. It was observed that the uncertainty increases with the return periods. $\mathrm{Hu}$ et al. (2015) estimated the uncertainty of hydrological design values by making use of the bootstrap method to estimate the standard deviation. The bootstrap method can be used to evaluate uncertainty in terms of bias, standard deviation and confidence bands. It is frequently applied in various fields, such as flood forecasting, water resources planning and climate change modelling (Prudhomme et al. 2003; Tiwari and Chatterjee 2010; Noguchi et al. 2011).

Another notable issue in the uncertainty assessment is the lack of adequate sample information, such as small sample sizes and short maximum rainfall series. The insufficient information inevitably leads to inaccurate quantification of the uncertainty related to the whole hydrological process, especially in the modelling of extreme rainfall values where the available observation data sets are scarce. For this reason, a long and complete series of rainfall output generated from the stochastic rainfall model is particularly useful. The stochastic rainfall model is a statistical tool used to generate arbitrarily long and complete synthetic rainfall series, enabling a more thorough representation of rainfall variability. The stochastic generation of rainfall is based on a random process where the sequences of random numbers simulated from computer algorithms are transformed into sequences of synthetic data which are statistically similar to the historical data. There are wide varieties of the stochastic weather generator developed in different regions, consisting of different simulation procedures according to the weather condition of 
the location of interest. The common examples are WGEN (Richardson 1981), LARS-WG (Semenov and Brooks 1999), MV-WG (Fodor et al. 2010) and WeaGETS (Chen et al. 2012).

Extreme rainfall event that leads to flooding is the most significant natural hazard in Malaysia which occurs due to very high intensity monsoon rainfall, heavy convective tropical rainstorms, rapid construction of buildings and other local factors. The Kelantan river basin is one of the areas in Malaysia where the monsoon flood has been occurring annually due to the northeast monsoon that brings heavy rainfalls and strong winds. The DDF curves or intensity duration frequency (IDF) curves have been established to describe the characteristics of the extreme rainfall and the information is used to aid in the design of flood mitigation infrastructures and assessment of flooding risk. The procedures of DDF and IDF curves construction are similar, except the former uses the maximum rainfall depth whereas the latter uses the maximum rainfall intensity. It is always important to evaluate the uncertainty of the DDF/IDF curves as the uncertainty is equally vital as the estimates themselves in any hydrological modelling. While many studies have been carried out to develop the DDF/IDF curves in this region (Ariff et al. 2012; Chang et al. 2013), researches on the evaluation of the uncertainty associated with the DDF/IDF curves are still rare. Lacking of the uncertainty information may lead to misleading predictions in the hydrological models and consequently pose much higher risk of failures in infrastructure design and implementation. It is crucial to carry out a comprehensive assessment of uncertainty estimates after the DDF model is constructed. Limited work on the uncertainty quantification of stochastic rainfall output had been done. In this study area which experiences tropical climate, no work on such matters has ever been carried out. The existing uncertainty analysis approaches usually quantify the uncertainty based on the historical rainfall series. For this study, the stochastic realisations of synthetic rainfall series were generated from the historical rainfall series using the stochastic rainfall generator. Therefore, the results of the uncertainty quantification or the estimated uncertainty were also from the stochastic rainfall generator. This paper is about the bootstrap-based methodological framework to investigate and evaluate the uncertainty of DDF curves based on the synthetic rainfall series. The bootstrap resampling technique was chosen due to its ease of implementation, conceptual simplicity and capability to provide accurate inferences without any distributional assumptions. The synthetic rainfall series were generated from a stochastic rainfall model, which was developed to generate the complete sequences of synthetic rainfall in the Kelantan river basin, Malaysia. The uncertainty analysis was carried out for 17 selected rainfall stations of the Kelantan river basin. The outcomes from this study can be used as a reference for the hydrological forecasting, infrastructure design, risk assessment and agricultural planning.

\section{Study area}

The Kelantan river basin is located at the northeastern part of Peninsular Malaysia between the latitudes $4^{\circ} 40^{\prime}-6^{\circ} 12^{\prime} \mathrm{N}$ and longitudes $101^{\circ} 20^{\prime}-102^{\circ} 20^{\prime} \mathrm{E}$ (figure 1 ). The region has a typical tropical climate due to the maritime exposure and proximity to the equator. The weather is hot and humid all the year round with uniform high temperature between $21^{\circ} \mathrm{C}$ and $32^{\circ} \mathrm{C}$ and high relative humidity ranging from $82 \%$ to $86 \%$. It has an annual rainfall of about $2700 \mathrm{~mm}$, which is mainly caused by the northeast monsoon that occurs from November to February. The northeast monsoon usually brings heavy rain to the study area and consequently leads to the monsoon floods. The southwest monsoon is considered as a drier period because the area is virtually sheltered by the Titiwangsa Range which runs down the peninsula. There are two inter-monsoon periods from March to April and September to October and convectional rain is expected during these periods.

\section{Methodology}

\subsection{Stochastic generation of rainfall series}

In this study, the historical daily rainfall series of 17 rainfall stations of the Kelantan river basin, Malaysia, were acquired from the Malaysian Meteorological Department (MMD). The spatial location and the summary statistics of all stations are given in figure 2 and table 1, respectively. A stochastic rainfall model was developed to stochastically generate a long and complete series of synthetic rainfall series based on the statistical characteristics of the historical rainfall series. Firstly, a simple but parsimonious two-state, first-order Markov model was used to simulate the rainfall 


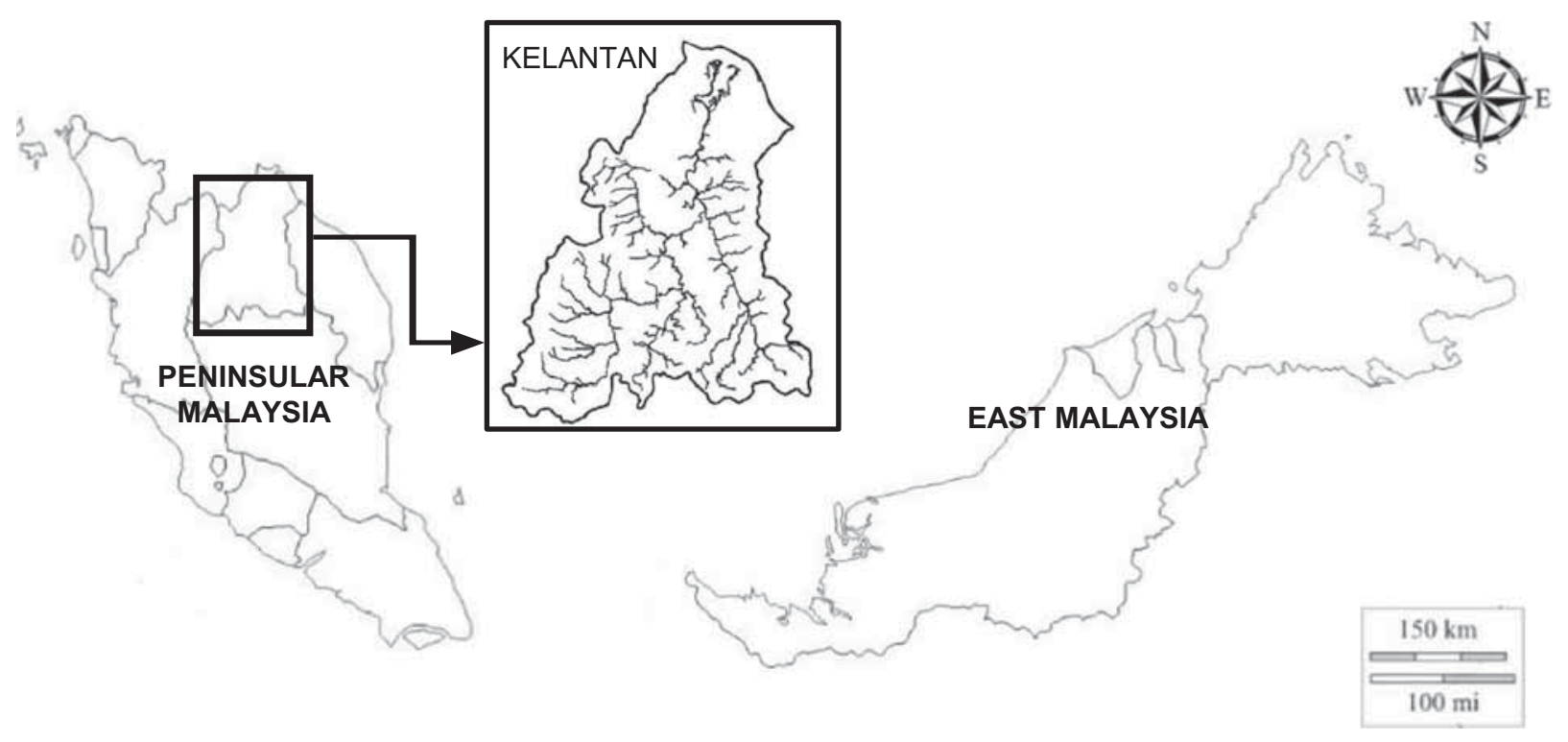

Figure 1. Location of the Kelantan river basin in Malaysia.

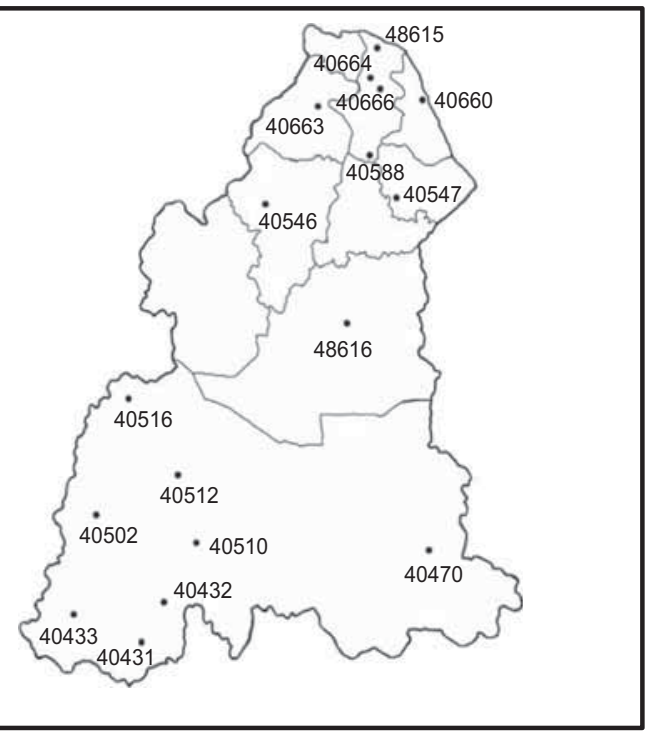

Figure 2. Location of 17 rainfall stations in the Kelantan river basin.

occurrence by generating the sequences of the wet and dry days. The probability of the occurrence of rainfall depends on the condition of the previous day, which can be expressed by two transition probabilities:

$$
\begin{aligned}
P_{01}= & \operatorname{Pr}\{\text { precipitation on day } t \\
& \text { no precipitation on day } t-1\},
\end{aligned}
$$

$$
\begin{aligned}
P_{11}= & \operatorname{Pr}\{\text { precipitation on day } t \mid \\
& \text { precipitation on day } t-1\} .
\end{aligned}
$$

Based on the simulated wet days, the rainfall amounts were simulated by using two-parameter log-normal distribution. Its probability density function is given as

$f(x)=\frac{1}{x q \sqrt{2 \pi}} \exp \left(-\frac{(\operatorname{In} x-s)^{2}}{2 q^{2}}\right), q>0, s>0$,

where $q$ and $s$ are the standard deviation and mean of the logarithmic transformed precipitation amount, respectively.

The parameters of the distributions were estimated using the maximum likelihood approach and subsequently used to simulate the synthetic daily rainfall series of five times the length of the historical rainfall series. In order to preserve the low-frequency variability of the rainfall, a spectral correction method suggested by Chen et al. (2010) was used to correct the monthly and interannual variability of the synthetic rainfall series.

The annual maximum rainfall series for event durations $(D)$ of $24,48,72,96$ and $120 \mathrm{~h}$ (hour) were extracted from the synthetic rainfall series. Since the frequency analysis of the hydrological time series is based on the stationarity assumption, 
Table 1. List of rainfall stations used in this study.

\begin{tabular}{llccc}
\hline Station code & \multicolumn{1}{c}{ Station name } & Record period & Latitude & Longitude \\
\hline 40431 & Pos Blau & $1978-2013$ & $04^{\circ} 39^{\prime} \mathrm{N}$ & $101^{\circ} 41^{\prime} \mathrm{E}$ \\
40432 & RPS Kuala Betis & $1974-2013$ & $04^{\circ} 42^{\prime} \mathrm{N}$ & $101^{\circ} 45^{\prime} \mathrm{E}$ \\
40433 & Pos Hau & $1978-2013$ & $04^{\circ} 42^{\prime} \mathrm{N}$ & $101^{\circ} 32^{\prime} \mathrm{E}$ \\
40470 & Pos Lebir & $1978-2013$ & $04^{\circ} 56^{\prime} \mathrm{N}$ & $102^{\circ} 23^{\prime} \mathrm{E}$ \\
40502 & Pos Bihai & $1978-2013$ & $05^{\circ} 00^{\prime} \mathrm{N}$ & $101^{\circ} 341^{\prime} \mathrm{E}$ \\
40510 & Pos Tehoi & $1978-2013$ & $05^{\circ} 03^{\prime} \mathrm{N}$ & $101^{\circ} 45^{\prime} \mathrm{E}$ \\
40512 & Pos Wias & $1978-2013$ & $05^{\circ} 07^{\prime} \mathrm{N}$ & $101^{\circ} 49^{\prime} \mathrm{E}$ \\
40516 & Pos Gob & $1978-2013$ & $05^{\circ} 17^{\prime} \mathrm{N}$ & $101^{\circ} 38^{\prime} \mathrm{E}$ \\
40547 & Mardi Jeram Pasu & $1984-2013$ & $05^{\circ} 48^{\prime} 46^{\prime \prime} \mathrm{N}$ & $102^{\circ} 20^{\prime} 40^{\prime \prime} \mathrm{E}$ \\
40546 & Pusat Ternakan Haiwan Tanah Merah & $1980-2013$ & $5^{\circ} 48^{\prime} 40^{\prime \prime} \mathrm{N}$ & $102^{\circ} 00^{\prime} 33^{\prime \prime} \mathrm{E}$ \\
40588 & Pusat Pertanian Melor & $1968-2013$ & $05^{\circ} 58^{\prime} \mathrm{N}$ & $102^{\circ} 18^{\prime} \mathrm{E}$ \\
40660 & Pusat Pertanian Bachok & $1974-2013$ & $6^{\circ} 03^{\prime} \mathrm{N}$ & $102^{\circ} 24^{\prime} \mathrm{E}$ \\
40663 & Pusat Pertanian Pasir Mas & $1976-2013$ & $06^{\circ} 02^{\prime} \mathrm{N}$ & $102^{\circ} 07^{\prime} \mathrm{E}$ \\
40664 & Pusat Pertanian Lundang & $1974-2013$ & $06^{\circ} 06^{\prime} \mathrm{N}$ & $02^{\circ} 14^{\prime} \mathrm{E}$ \\
40666 & Mardi Kubang Keranji & $1982-2013$ & $06^{\circ} 05^{\prime} \mathrm{N}$ & $102^{\circ} 17^{\prime} \mathrm{E}$ \\
48615 & Kota Bharu & $1954-2013$ & $06^{\circ} 10^{\prime} \mathrm{N}$ & $102^{\circ} 18^{\prime} \mathrm{E}$ \\
48616 & Kuala Krai & $1986-2013$ & $05^{\circ} 32^{\prime} \mathrm{N}$ & $102^{\circ} 12^{\prime} \mathrm{E}$ \\
\hline
\end{tabular}

the augmented Dickey-Fuller test (Dickey and Fuller 1979) was used to examine the stationarity of the annual maximum series. The augmented Dickey-Fuller test examines the temporal trends of the annual maximum series and tests for the presence of unit roots. The null hypothesis of the augmented Dickey-Fuller tests stated that there is a unit root for the data sets, indicating nonstationarity of the annual maximum series. The tests were conducted at the level of $5 \%$ significance.

\subsection{Bootstrap resampling technique}

In this study, the bootstrap resampling technique was employed to estimate the sampling distribution of statistics and quantify the uncertainty of the rainfall DDF curves. The main idea of the bootstrap is to generate large samples with replacement by resampling from the original samples based on the assumption that the samples are independent and identically distributed. The sample values are treated as similarly as possible to the underlying true distribution from which it is drawn. This method has been advocated not just because of its computational efficiency, but as an easyto-implement approach that generates bootstrap replications without relying on the assumption of true distribution. It is applicable by just depending on the information obtained from the sample values.

The steps of the bootstrap method employed in this study are described as follows:
(1) Assume that the annual maximum rainfall series for the durations of $24,48,72,96$ and $120 \mathrm{~h}$ are the original samples, which are denoted as $X=\left(X_{1}, X_{2}, \ldots, X_{n}\right)$ for $n=$ total length of annual maximum rainfall records.

(2) Produce bootstrap samples of annual maximum rainfall series by the bootstrapping process, which involves randomly picking values with replacement from the original sample. Resampling was carried out at all rainfall stations for each duration under consideration.

Repeat the bootstrap resampling process $10^{4}$ times to generate $10^{4}$ bootstrap samples, which are $X^{*}=$ $\left(X_{1}^{*(i)}, X_{2}^{*(i)}, \ldots, X_{n}^{*(i)}\right)$, where $i=1,2, \ldots, m$ and $m$ is the size of the resampling $\left(10^{4}\right)$. Such a large sample size of the bootstrap replications can ensure a reliable and accurate estimation of the statistical parameter of interest.

\subsection{Frequency analysis of extreme rainfall series}

\subsubsection{Fitting the GEV distribution}

To perform the uncertainty analysis of the DDF curves, a very crucial step is the frequency analysis of extreme rainfall events. Therefore, GEV distribution was adopted in this study to fit the $10^{4}$ bootstrap samples of the annual maximum rainfall series. The cumulative distribution function of GEV distribution (Jenkinson 1955) can be expressed as 


$$
\begin{aligned}
& F(x)=\exp \left\{-\left[1+\frac{\gamma(x-\mu)}{\sigma}\right]^{-\frac{1}{\gamma}}\right\} \text { for } \gamma \neq 0, \\
& F(x)=\exp \left\{-\exp \left[-\frac{(x-\mu)}{\sigma}\right]\right\} \text { for } \gamma=0,
\end{aligned}
$$

where $x$ is the rainfall amount, $\gamma, \mu$ and $\sigma$ are the shape, location and scale parameters, respectively. The quantile function of GEV distribution with the cumulative probability $z$ is defined as

$$
\begin{aligned}
& x_{z}=\mu+\frac{\sigma}{\gamma}\left[1-(-\ln (z))^{\gamma}\right], \quad \text { for } \gamma \neq 0, \\
& x_{z}=\mu-\sigma \ln (-\ln (z)), \quad \text { for } \gamma=0 .
\end{aligned}
$$

\subsubsection{Parameter estimation using L-moments}

The selection of the parameter estimation method usually considers the description of a wider range of distributions with the least computational efforts. The method of L-moments is preferable over the conventional moments because it is more robust to the sampling variability and outliers of data, relatively less biased in the estimation process, and free from sample-size-related bounds (Hosking 1990; Kyselý and Dubrovský 2005; Borujeni and Sulaiman 2009; Ngongondo et al. 2011; Hailegeorgis et al. 2013). Therefore, the method of L-moments was used in this study to derive the parameters of the GEV distribution as it can describe the location, skewness, kurtosis, shape and other aspects of the probability distribution. The L-moments are based on the probability weighted moment which can be expressed as (Hosking 1990)

$P_{r}=(r+1)^{-1}\left\{\mu+\frac{\sigma}{\gamma}\left[1-(r+1)^{-\gamma} \Gamma(1+\gamma)\right]\right\}$,

where $\Gamma$ is the gamma function. The unbiased estimator of $P_{r}$ is expressed as (Landwehr et al. 1979; Hosking and Wallis 1995)

$$
\hat{P}_{r}=\frac{1}{n} \sum_{i=1}^{n} \frac{(i-1)(i-2) \ldots(i-r)}{(n-1)(n-2) \ldots(n-r)} x_{i},
$$

where $x_{i}$ is the data value of the annual maximum arranged in ascending order. The sample L-moments are given as

$$
\begin{aligned}
& \ell_{1}=\hat{P}_{0}, \\
& \ell_{2}=2 \hat{P}_{1}-\hat{P}_{0}, \\
& \ell_{3}=6 \hat{P}_{2}-6 \hat{P}_{1}+\hat{P}_{0} .
\end{aligned}
$$

The estimates of the GEV parameters are subsequently estimated as

$$
\begin{aligned}
& \hat{\gamma}=7.8590 c+2.9554 c^{2}, \\
& \hat{\sigma}=\frac{\ell_{2} \hat{\gamma}}{\Gamma(1+\hat{\gamma})\left(1-2^{-\hat{\gamma}}\right)}, \\
& \hat{\mu}=\ell_{1}+\frac{\hat{\sigma}}{\hat{\gamma}}[1-\Gamma(1+\hat{\gamma})],
\end{aligned}
$$

where

$$
c=\frac{2}{3+\ell_{3} / \ell_{2}}-\frac{\ln 2}{\ln 3} .
$$

For the present study, $\hat{\alpha}=\hat{\sigma} / \widehat{\mu}$ was considered. The annual maximum rainfall series of durations

\begin{tabular}{|c|c|c|c|c|c|c|}
\hline & \multicolumn{3}{|c|}{ Monthly } & \multicolumn{3}{|c|}{ Yearly } \\
\hline & $\begin{array}{c}\text { Mann-Whitney } \\
\text { tests }\end{array}$ & $\mathrm{K}-\mathrm{S}$ tests & $\begin{array}{c}\text { Squared ranks } \\
\text { tests } \\
\end{array}$ & $\begin{array}{c}\text { Mann-Whitney } \\
\text { tests }\end{array}$ & $\mathrm{K}-\mathrm{S}$ tests & $\begin{array}{c}\text { Squared ranks } \\
\text { tests }\end{array}$ \\
\hline Wet spells & $204 / 204$ & $202 / 204$ & $202 / 204$ & $16 / 17$ & $14 / 17$ & $6 / 17$ \\
\hline Dry spells & $204 / 204$ & $202 / 204$ & $202 / 204$ & $16 / 17$ & $11 / 17$ & $8 / 17$ \\
\hline Rainfall amounts & $203 / 204$ & $189 / 204$ & $202 / 204$ & $17 / 17$ & $15 / 17$ & $17 / 17$ \\
\hline
\end{tabular}
24, 48, 72, 96 and $120 \mathrm{~h}$ at all stations were fitted to the GEV distribution by means of L-moments.

\subsection{Development of the rainfall DDF curves}

In this section, the rainfall DDF curves were derived from the relationships incorporating the GEV parameters as functions of duration. The rainfall depth, $x(\mathrm{~mm})$ was plotted against all considered durations for return periods of $2,5,10,20$, 50 and $100 \mathrm{yr}$. The general linear regression model was used to model the GEV parameters

Table 2. Results of the validation tests (Mann-Whitney, K-S and squared ranks tests). 


$$
\lambda=X \beta+e,
$$

Table 3. Augmented Dickey-Fuller test results for the annual maximum rainfall series $(D=24 h)$.

\begin{tabular}{lc}
\hline Station name & $P$-value \\
\hline Pos Blau & $<0.0001$ \\
RPS Kuala Betis & 0.0002 \\
Pos Hau & 0.00271 \\
Pos Lebir & $<0.0001$ \\
Pos Bihai & $<0.0001$ \\
Pos Tehoi & 0.0006 \\
Pos Wias & 0.0044 \\
Pos Gob & $<0.0001$ \\
Mardi Jeram Pasu & 0.0005 \\
Pusat Ternakan Haiwan Tanah Merah & $<0.0001$ \\
Pusat Pertanian Melor & 0.0003 \\
Pusat Pertanian Bachok & 0.0010 \\
Pusat Pertanian Pasir Mas & 0.0002 \\
Pusat Pertanian Lundang & $<0.0001$ \\
Mardi Kubang Keranji & $<0.0001$ \\
Kota Bharu & 0.0001 \\
Kuala Krai & $<0.0001$ \\
\hline
\end{tabular}
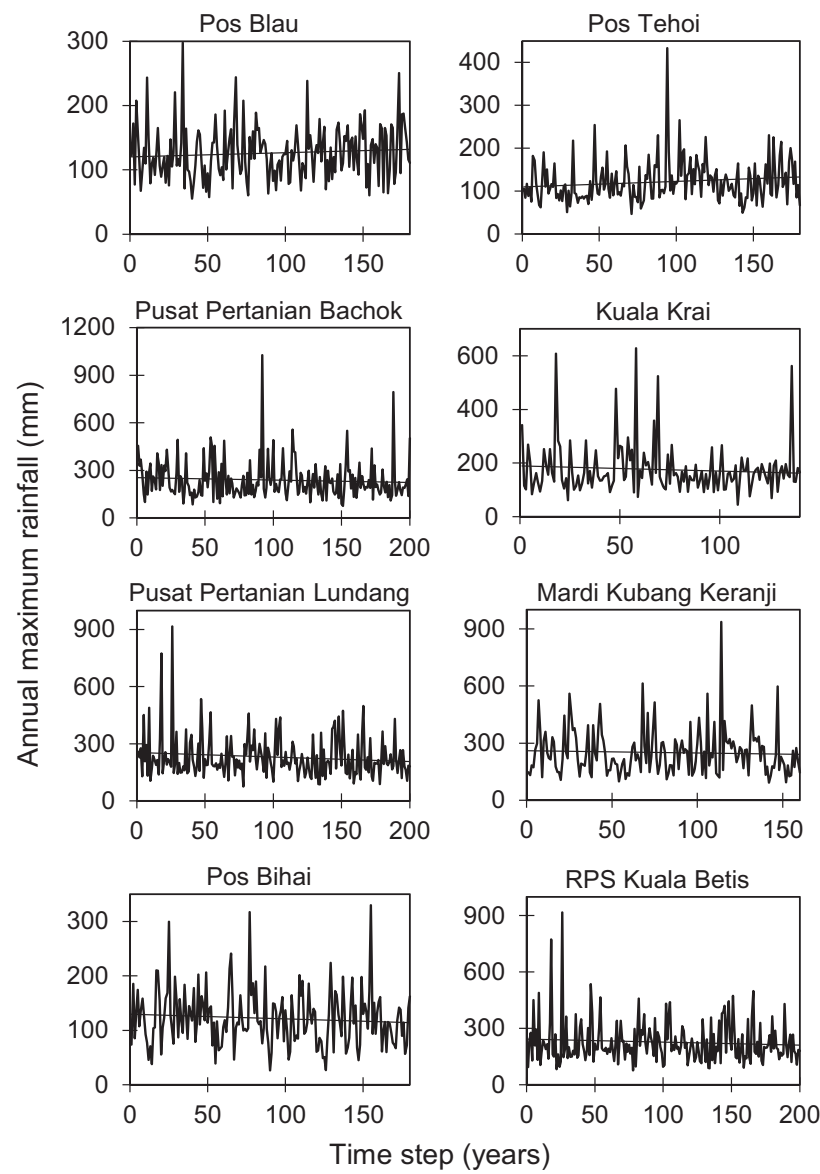

Figure 3. Trends of annual maximum rainfall $(D=24 \mathrm{~h})$ at eight randomly selected stations. where

$$
\begin{aligned}
& X=\left(\begin{array}{cc}
1 & \ln D_{1} \\
\cdot & \cdot \\
1 & \ln D_{6}
\end{array}\right), \\
& \beta=\left(\begin{array}{l}
\beta_{1} \\
\beta_{2}
\end{array}\right) .
\end{aligned}
$$

In general, $\lambda$ is a $(n \times 1)$ vector of the GEV parameters of length $n, X$ is a $(n \times k)$ known matrix of full rank, $\beta$ is a $(p \times 1)$ vector of regression coefficients, $e$ is a $(n \times 1)$ vector of random errors and $D$ is the rainfall duration. The regression coefficients $\left(\beta_{1}\right.$ and $\left.\beta_{2}\right)$ were determined by using the generalised least-squares method (Madsen and Rosbjerg 1997; Madsen et al. 2002; Haddad et al. 2010). The generalised least-squares method is able to consider the sampling variability explicitly and give an accurate estimation of the parameter sampling variances and parameter estimators. The
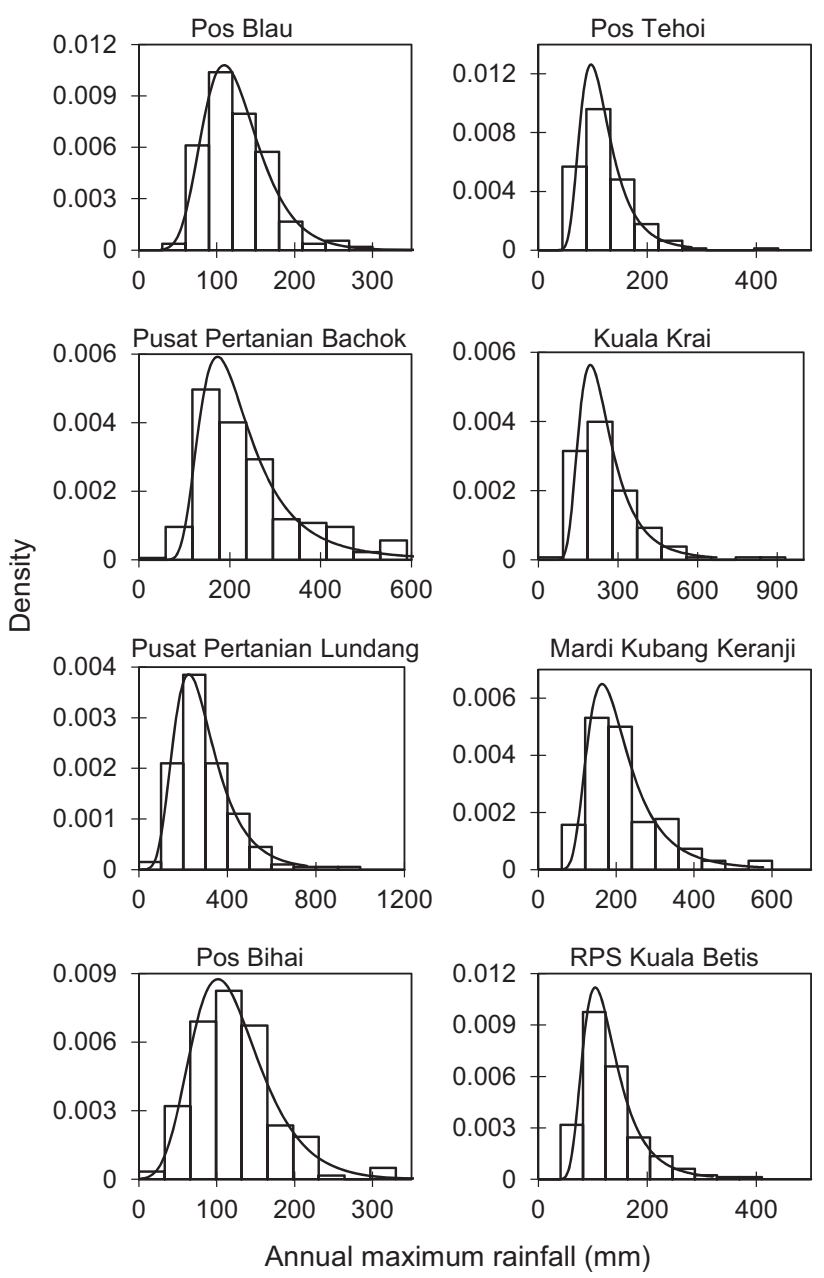

Figure 4. Histograms of annual maximum rainfall series ( $D=24 \mathrm{~h}$ ) fitted to the GEV distribution at eight randomly selected stations. 
Table 4. Estimated GEV parameters for $D=24,48,72,96$, and 120 h at eight randomly selected stations. Their corresponding standard deviations are given in brackets.

\begin{tabular}{|c|c|c|c|c|c|c|}
\hline \multirow[b]{2}{*}{$D(\mathrm{~h})$} & \multicolumn{3}{|c|}{ Pos Blau } & \multicolumn{3}{|c|}{ Pos Tehoi } \\
\hline & $\hat{\gamma}$ & $\hat{\mu}$ & $\hat{\alpha}$ & $\hat{\gamma}$ & $\hat{\mu}$ & $\hat{\alpha}$ \\
\hline 24 & $0.081(0.057)$ & $108.369(3.011)$ & $0.320(0.018)$ & $0.094(0.068)$ & $99.321(2.817)$ & $0.325(0.020)$ \\
\hline 48 & $0.098(0.060)$ & $123.550(3.274)$ & $0.312(0.018)$ & $0.042(0.046)$ & $116.300(2.710)$ & $0.290(0.023)$ \\
\hline 72 & $0.172(0.104)$ & $131.640(3.701)$ & $0.314(0.020)$ & $-0.003(0.049)$ & $127.008(3.226)$ & $0.310(0.019)$ \\
\hline 96 & $0.186(1.255)$ & $135.740(3.261)$ & $0.325(0.019)$ & $-0.028(0.059)$ & $130.006(3.724)$ & $0.340(0.018)$ \\
\hline \multirow[t]{2}{*}{120} & $0.143(0.072)$ & $132.857(4.060)$ & $0.380(0.028)$ & $-0.044(0.060)$ & $125.222(4.126)$ & $0.385(0.021)$ \\
\hline & \multicolumn{3}{|c|}{ Pusat Pertanian Bachok } & \multicolumn{3}{|c|}{ Kuala Krai } \\
\hline$D(\mathrm{~h})$ & $\hat{\gamma}$ & $\hat{\mu}$ & $\hat{\alpha}$ & $\hat{\gamma}$ & $\hat{\mu}$ & $\hat{\alpha}$ \\
\hline 24 & $0.174(0.06)$ & $182.750(5.875)$ & $0.389(0.023)$ & $0.233(0.078)$ & $134.390(4.340)$ & $0.348(0.028)$ \\
\hline 48 & $0.152(0.059)$ & $215.851(6.506)$ & $0.372(0.022)$ & $0.165(0.071)$ & $166.216(5.315)$ & $0.349(0.027)$ \\
\hline 72 & $0.109(0.046)$ & $237.338(7.003)$ & $0.364(0.021)$ & $0.165(0.065)$ & $186.402(6.116)$ & $0.356(0.026)$ \\
\hline 96 & $0.067(0.048)$ & $251.735(7.761)$ & $0.390(0.024)$ & $0.113(0.068)$ & $203.179(6.679)$ & $0.350(0.023)$ \\
\hline \multirow[t]{2}{*}{120} & $0.029(0.047)$ & $263.998(8.565)$ & $0.412(0.025)$ & $0.055(0.071)$ & $213.516(7.598)$ & $0.386(0.029)$ \\
\hline & \multicolumn{3}{|c|}{ Pusat Pertanian Lundang } & \multicolumn{3}{|c|}{ Mardi Kubang Keranji } \\
\hline$D(\mathrm{~h})$ & $\hat{\gamma}$ & $\hat{\mu}$ & $\hat{\alpha}$ & $\hat{\gamma}$ & $\hat{\mu}$ & $\hat{\alpha}$ \\
\hline 24 & $0.161(0.059)$ & $178.908(5.329)$ & $0.371(0.023)$ & $0.112(0.064)$ & $194.166(7.449)$ & $0.412(0.022)$ \\
\hline 48 & $0.076(0.057)$ & $214.702(6.906)$ & $0.396(0.022)$ & $0.094(0.066)$ & $239.076(8.172)$ & $0.386(0.024)$ \\
\hline 72 & $0.061(0.056)$ & $242.296(7.492)$ & $0.389(0.021)$ & $0.052(0.054)$ & $270.115(8.775)$ & $0.373(0.025)$ \\
\hline 96 & $-0.001(0.049)$ & $262.682(8.161)$ & $0.397(0.023)$ & $-0.012(0.055)$ & $290.522(10.878)$ & $0.415(0.023)$ \\
\hline \multirow[t]{2}{*}{120} & $-0.022(0.052)$ & $274.365(9.277)$ & $0.425(0.025)$ & $-0.030(0.058)$ & 314.369 (12.237) & $0.438(0.028)$ \\
\hline & \multicolumn{3}{|c|}{ Pos Bihai } & \multicolumn{3}{|c|}{ RPS Kuala Betis } \\
\hline$D(\mathrm{~h})$ & $\hat{\gamma}$ & $\hat{\mu}$ & $\hat{\propto}$ & $\hat{\gamma}$ & $\hat{\mu}$ & $\hat{\propto}$ \\
\hline 24 & $-0.075(0.063)$ & $100.220(3.567)$ & $0.425(0.025)$ & $0.119(0.052)$ & $107.422(2.863)$ & $0.335(0.021)$ \\
\hline 48 & $-0.066(0.067)$ & $118.227(3.972)$ & $0.407(0.025)$ & $0.115(0.057)$ & $126.338(3.140)$ & $0.315(0.020)$ \\
\hline 72 & $-0.089(0.074)$ & $132.460(4.576)$ & $0.418(0.026)$ & $0.099(0.061)$ & $139.931(3.462)$ & $0.313(0.019)$ \\
\hline 96 & $-0.136(0.055)$ & $143.379(5.136)$ & $0.423(0.024)$ & $0.047(0.063)$ & $151.545(3.929)$ & $0.328(0.019)$ \\
\hline 120 & $-0.114(0.054)$ & $151.243(5.196)$ & $0.410(0.023)$ & $-0.012(0.054)$ & $156.039(4.240)$ & $0.345(0.020)$ \\
\hline
\end{tabular}

generalised least-squares estimate of the parameter vector is given as

$$
\hat{\beta}_{\mathrm{gls}}=\left(X^{\mathrm{T}} C^{-1} X\right)^{-1} X^{\mathrm{T}} C^{-1} \lambda
$$

where $C$ is the covariance matrix of $\lambda$. The generalised least-squares method was applied to the $10^{4}$ bootstrap samples to obtain the regression coefficients and subsequently establish the relationship between the GEV parameters for various duration periods. Subsequently, the relationship between the GEV parameters as functions of the duration to derive the DDF curves is defined as:

\subsection{Uncertainty quantification of the rainfall DDF curves}

Based on the steps of modelling the rainfall DDF relationships as shown above, the estimation of the GEV parameters is subjected to uncertainty, which is known as the parameter uncertainty. The parameter uncertainty is due to the sampling error or the inability of the GEV distribution to describe the model inputs and parameters completely. For each duration $(24,48,72,96$ and $120 \mathrm{~h}$ ) of time step $1 \mathrm{~h}$, there are $10^{4}$ rainfall depths derived from the $10^{4}$ rainfall DDF curves

$\hat{x}(T)=\exp \left(\hat{\beta}_{1 \mu}+\hat{\beta}_{2 \mu} \ln D\right) \times\left(1+\left(\hat{\beta}_{1 \propto}+\hat{\beta}_{2 \propto} \ln D\right) \frac{\left\{1-\left[-\ln \left(1-T^{1}\right)\right]^{\left(\hat{\beta}_{1 \gamma}+\hat{\beta}_{2 \gamma} \ln D\right)}\right\}}{\left(\hat{\beta}_{1 \gamma}+\hat{\beta}_{2 \gamma} \ln D\right)}\right)$. 
Table 5. Estimated regression coefficients of eight randomly selected stations.

\begin{tabular}{|c|c|c|c|c|c|c|c|c|}
\hline \multirow[b]{2}{*}{ GEV parameter } & \multicolumn{4}{|c|}{ Pos Blau } & \multicolumn{4}{|c|}{ Pos Tehoi } \\
\hline & $\hat{\beta}_{1}$ & $\sigma\left(\hat{\beta}_{1}\right)$ & $\hat{\beta}_{2}$ & $\sigma\left(\hat{\beta}_{2}\right)$ & $\hat{\beta}_{1}$ & $\sigma\left(\hat{\beta}_{1}\right)$ & $\hat{\beta}_{2}$ & $\sigma\left(\hat{\beta}_{2}\right)$ \\
\hline $\ln \mu$ & 4.426 & 0.012 & 0.146 & 0.002 & 4.275 & 0.011 & 0.156 & 0.003 \\
\hline$\propto$ & 0.295 & 0.016 & -0.001 & 0.004 & 0.100 & 0.021 & 0.055 & 0.004 \\
\hline \multirow[t]{2}{*}{$\underline{\gamma}$} & 0.113 & 0.062 & -0.053 & 0.013 & 0.380 & 0.047 & -0.088 & 0.011 \\
\hline & \multicolumn{4}{|c|}{ Pusat Pertanian Bachok } & \multicolumn{4}{|c|}{ Kuala Krai } \\
\hline GEV parameter & $\hat{\beta}_{1}$ & $\sigma\left(\hat{\beta}_{1}\right)$ & $\hat{\beta}_{2}$ & $\sigma\left(\hat{\beta}_{2}\right)$ & $\hat{\beta}_{1}$ & $\sigma\left(\hat{\beta}_{1}\right)$ & $\hat{\beta}_{2}$ & $\sigma\left(\hat{\beta}_{2}\right)$ \\
\hline $\ln \mu$ & 4.548 & 0.037 & 0.214 & 0.010 & 3.953 & 0.021 & 0.298 & 0.003 \\
\hline$\propto$ & 0.126 & 0.054 & 0.063 & 0.013 & 0.328 & 0.023 & 0.007 & 0.004 \\
\hline \multirow[t]{2}{*}{$\gamma$} & 0.726 & 0.094 & -0.150 & 0.021 & 0.386 & 0.097 & -0.059 & 0.019 \\
\hline & \multicolumn{4}{|c|}{ Pusat Pertanian Lundang } & \multicolumn{4}{|c|}{ Mardi Kubang Keranji } \\
\hline GEV parameter & $\hat{\beta}_{1}$ & $\sigma\left(\hat{\beta}_{1}\right)$ & $\hat{\beta}_{2}$ & $\overline{\sigma\left(\hat{\beta}_{2}\right)}$ & $\hat{\beta}_{1}$ & $\sigma\left(\hat{\beta}_{1}\right)$ & $\hat{\beta}_{2}$ & $\sigma\left(\hat{\beta}_{2}\right)$ \\
\hline $\ln \mu$ & 4.349 & 0.019 & 0.268 & 0.004 & 4.315 & 0.022 & 0.299 & 0.003 \\
\hline$\propto$ & 0.254 & 0.025 & 0.035 & 0.005 & 0.351 & 0.026 & 0.012 & 0.006 \\
\hline \multirow[t]{2}{*}{$\gamma$} & 0.570 & 0.087 & -0.127 & 0.017 & 0.419 & 0.084 & -0.090 & 0.018 \\
\hline & \multicolumn{4}{|c|}{ Pos Bihai } & \multicolumn{4}{|c|}{ RPS Kuala Betis } \\
\hline GEV parameter & $\hat{\beta}_{1}$ & $\sigma\left(\hat{\beta}_{1}\right)$ & $\hat{\beta}_{2}$ & $\sigma\left(\hat{\beta}_{2}\right)$ & $\hat{\beta}_{1}$ & $\sigma\left(\hat{\beta}_{1}\right)$ & $\hat{\beta}_{2}$ & $\sigma\left(\hat{\beta}_{2}\right)$ \\
\hline $\ln \mu$ & 3.731 & 0.026 & 0.258 & 0.004 & 3.811 & 0.020 & 0.245 & 0.002 \\
\hline$\propto$ & 0.449 & 0.020 & -0.009 & 0.003 & 0.413 & 0.022 & -0.018 & 0.003 \\
\hline$\gamma$ & -0.035 & 0.072 & -0.016 & 0.016 & 0.160 & 0.039 & -0.029 & 0.010 \\
\hline
\end{tabular}

and ranked in increasing order. The $95 \%$ confidence interval was used as an indicator to quantify the uncertainty of the estimation. The $95 \%$ confidence interval was denoted as the 2.5th (lower bound) and 97.5th percentiles (upper bound) of the bootstrap estimates. Therefore, the 250th and 9750th values were obtained from the ranked rainfall depths and plotted to estimate the $95 \%$ confidence interval for the rainfall depth quantile estimation.

Next, the distribution of the bootstrapped rainfall quantiles was represented by a normal distribution, which consists of two parameters, namely, mean and standard deviation. The standard deviation was generated from the $10^{4}$ bootstrap samples and modelled as a function of the duration and the return period. The fitting procedure involved five durations ( $D=24,48$, 72,96 and $120 \mathrm{~h}$ ) and six return periods $(T=$ $2,5,10,20,50$ and $100 \mathrm{yr}$ ). The ordinary leastsquares method was adopted to estimate the regression coefficients. Finally, the lower bounds and upper bounds of the confidence intervals were fitted to the normal distribution and plotted on the DDF curves to describe the uncertainty of the DDF curves.

\section{Results and discussions}

\subsection{Analysis of the synthetic rainfall series}

The ability of the stochastic rainfall model to represent the mean, frequency distribution and standard deviation of rainfall was evaluated by using the Mann-Whitney, Kolmogorov-Smirnov $(\mathrm{K}-\mathrm{S})$ and squared ranks tests. The results of the validation tests for the station-month (17 stations $\times 12$ months) and station-year (17 stations $\times 1 \mathrm{yr})$ combinations are presented in table 2 . It appears that most of the station-month and station-year combinations of the rainfall occurrences and rainfall amounts passed all three validation tests. For example, the monthly wet spells and dry spells of all 204 station-month combinations passed the Mann-Whitney tests. This indicated that the firstorder Markov model and the log-normal distribution can reproduce the important properties of the rainfall occurrences and rainfall amounts, respectively. Therefore, the synthetic rainfall series were well validated and reliable to be used for further analysis.

Next, the results of the stationarity of the annual maximum rainfall series are presented in 
table 3. It can be observed that the computed $P$-values of all rainfall stations were lower than the significance level of $5 \%$. This implied that there were no unit roots for the annual maximum rainfall series and the alternative hypothesis that stated that the time series are stationary was accepted. Figure 3 further shows that the annual maximum rainfall series fitted with its temporal trend. For simplicity and without the loss of generality, the results are presented for the eight randomly selected rainfall stations out of the total 17 rainfall stations. It is apparent from figure 3 that the series appears to be constant over time. This indicated that the trend of the annual maximum rainfall series with time was not statistically significant, and thus, the stationarity assumption was valid.

\subsection{Goodness-of-fit and parameters of the GEV distribution}

GEV distribution has been applied in the frequency analysis of the annual maximum rainfall series where the main concern is to model the behaviour of the upper tail. The histograms of the GEV distribution fit were constructed to inspect the predictive ability of the distribution. The density values were plotted as the $y$-axis values. The density value $D$ is defined as:

$$
D=\frac{f r}{n * w},
$$

where $f r$ is the frequency of each interval, $n$ is the total number of samples and $w$ is the width of each interval. Figure 4 shows the excellent fit of the GEV distribution as the histograms of the annual maximum rainfall series were a good match with the probability density function of the fitted GEV model. This confirmed that the selection of the GEV distribution for the frequency analysis of this study area is a practically good choice. GEV distribution has the additional shape parameter other than the scale and location parameters for a better description of the upper tail of the extreme rainfall series. The results are consistent with those of Zalina et al. (2002) and Win and Win (2014) who found that GEV distribution gave good performance in fitting the maximum rainfall series in several areas of Malaysia.

The estimated GEV parameters $(\hat{\gamma}, \hat{\mu}, \hat{\alpha})$ and their corresponding standard deviations are presented in table 4 . The values of the standard deviation reflect the presence of possible uncertainty arising from sampling variability. It was
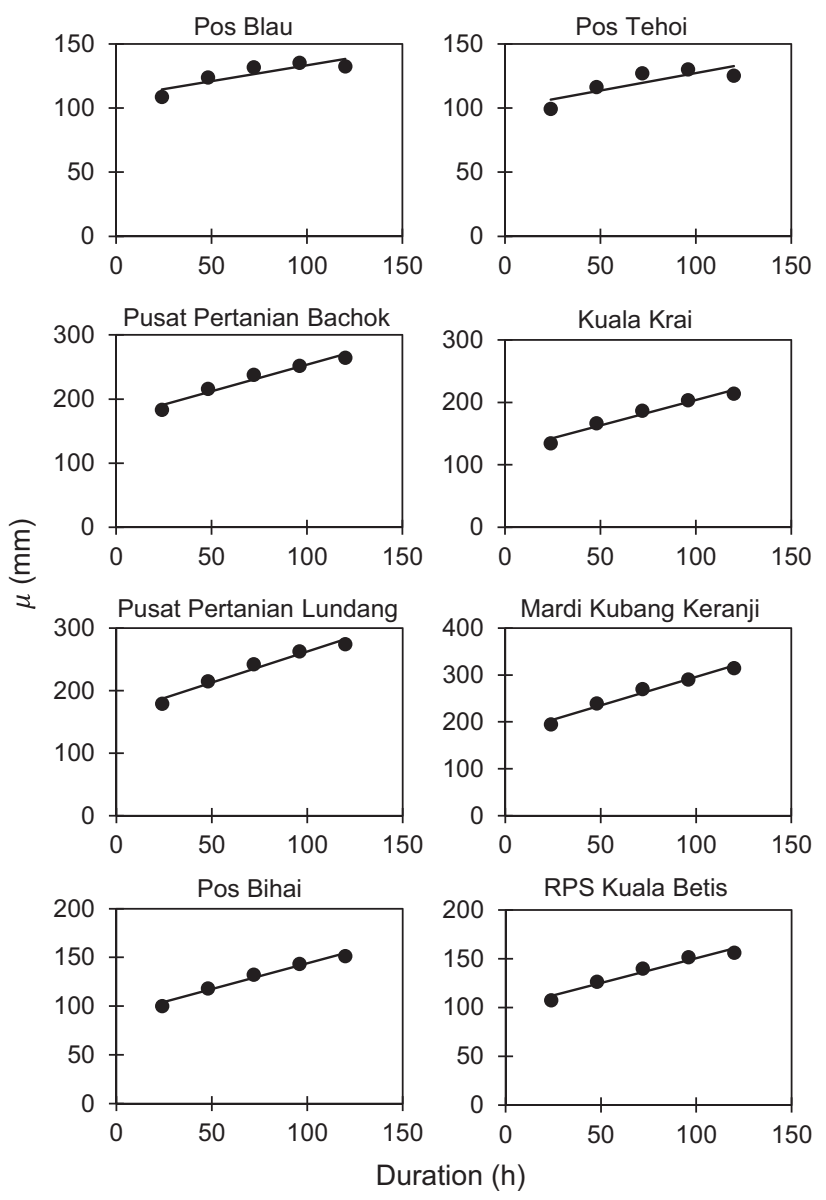

Figure 5. Parameter $\mu$ plotted against duration $D$ at the eight randomly selected stations.

shown that the values of parameter $\hat{\mu}$ increased with the event durations. This is in good agreement with the findings of Overeem et al. (2008) and Mirzaei et al. (2013). For the parameters $\hat{\gamma}$ and $\hat{\alpha}$, they were unlikely to decrease with decreasing duration. The mean and standard deviation of the estimated regression coefficients were calculated and are presented in table 5. It was shown that there were systematic variations of the GEV parameters with the durations as the estimates of two slopes $\left(\beta_{1}\right.$ and $\left.\beta_{2}\right)$ were not zero. This is further displayed in figure 5 that the parameter $\mu$ increased with the durations.

\subsection{Uncertainty features of DDF curves}

The DDF curves relate the rainfall depth, duration and frequency to generate the rainfall frequency at any intermediate duration and return period. The resulting DDF curves are presented in figure 6 for the eight randomly selected stations. It was shown that the rainfall depths increase with the durations 

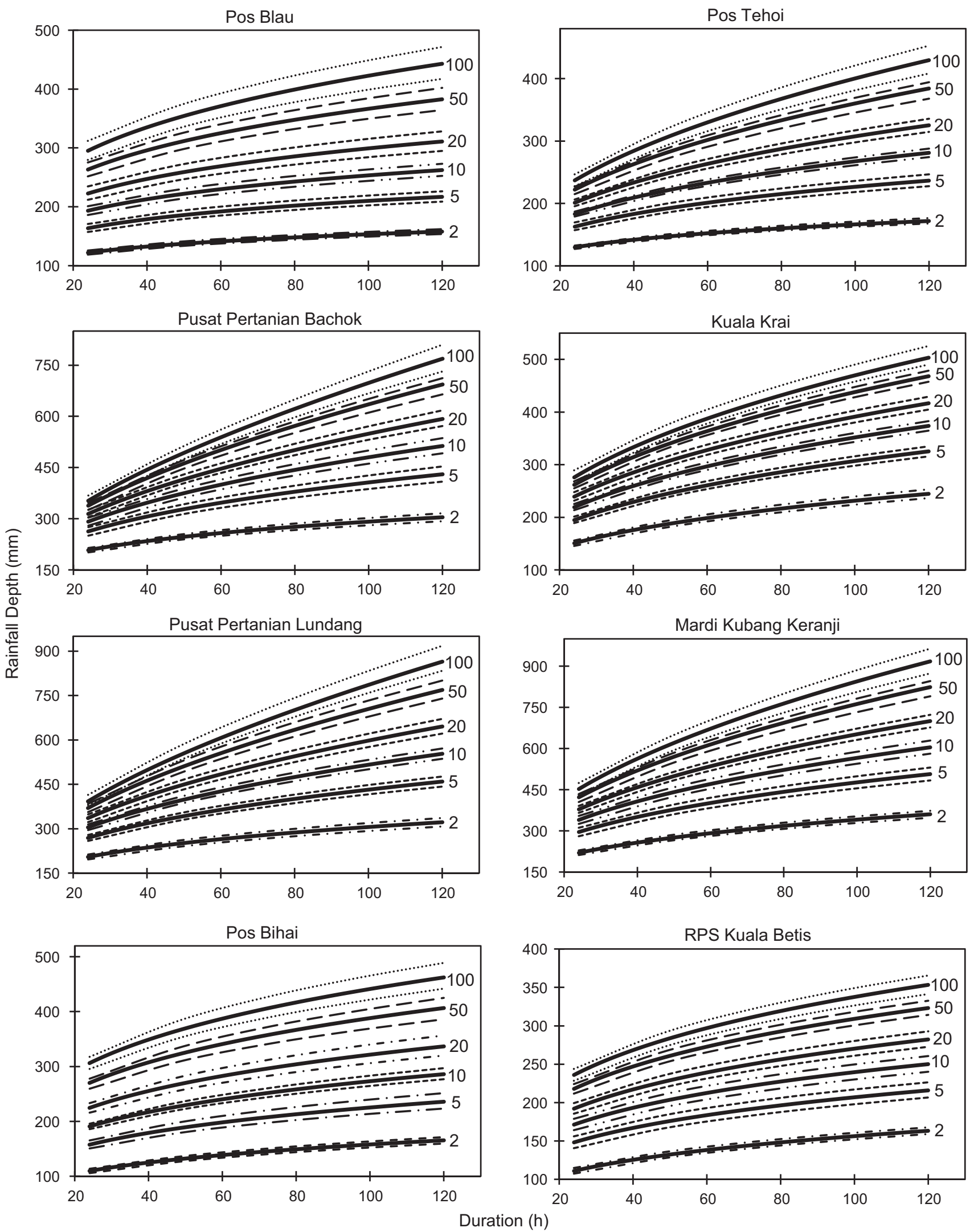

Figure 6. Rainfall DDF curves (solid lines) and $95 \%$ confidence intervals (dashed lines) for the return periods of $2,5,10$, 20, 50, and $100 \mathrm{yr}$ at eight randomly selected stations. 

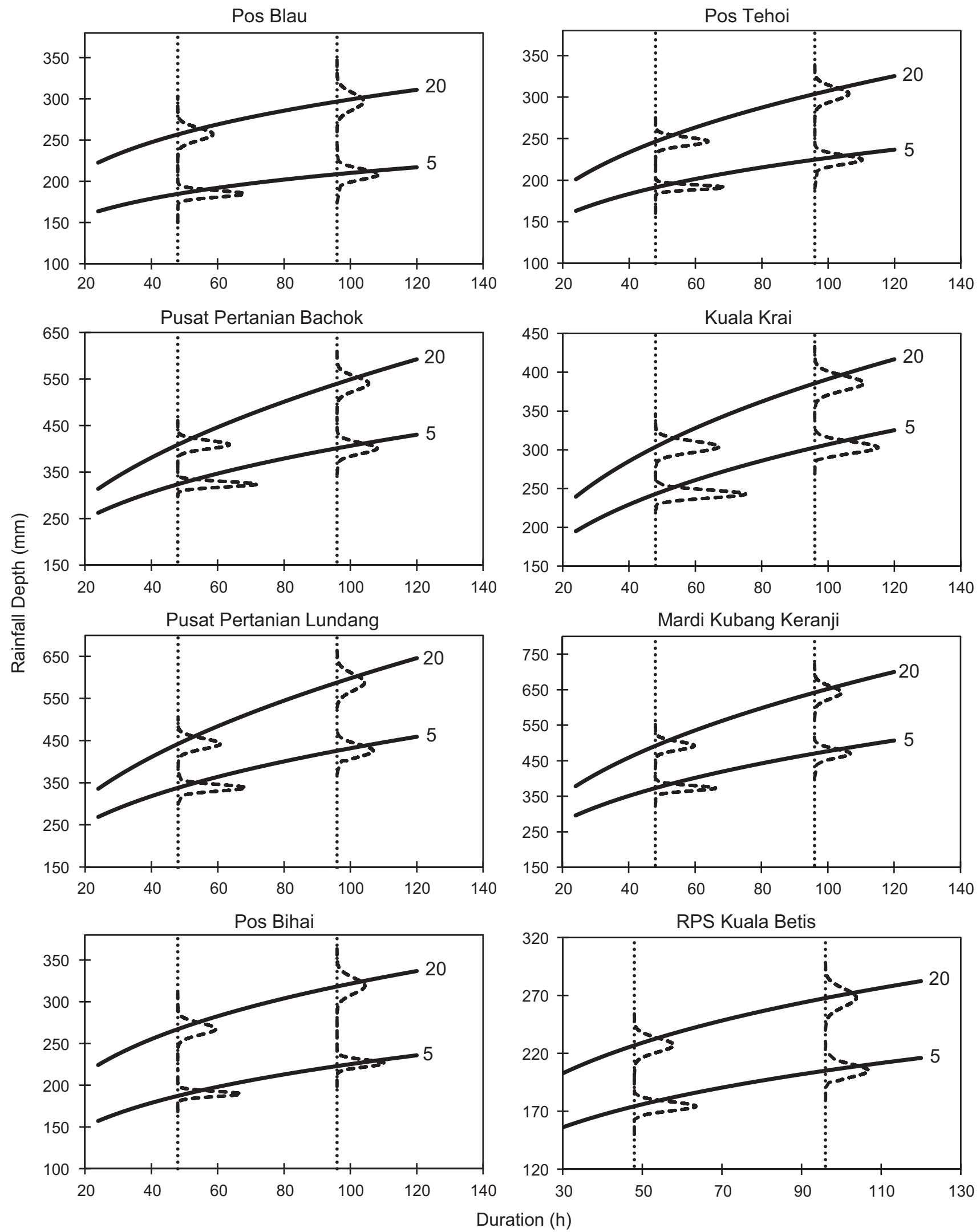

Figure 7. Rainfall DDF curves (solid lines) and the normal probability density functions (dashed lines) which describe the bootstrap distribution at $D=48$ and $96 \mathrm{~h}$. 
of all return periods. For example, as shown in the Pos Blau station, for a duration of $24-120 \mathrm{~h}$ within a $100-y r$ return period, the rainfall depths showed an increase from 295 to $443 \mathrm{~mm}$.

From the confidence bounds of the DDF curves, it was apparent that with the increasing return periods, the lower bounds and upper bounds of the $95 \%$ confidence interval were getting larger. For instance, as shown at the Pos Blau station, the 95\% confidence interval of the rainfall depth quantiles for a duration of $24 \mathrm{~h}$ varies from 119 to $125 \mathrm{~mm}$ for a return period of $2 \mathrm{yr}$ to 280 to $312 \mathrm{~mm}$ for a return period of $100 \mathrm{yr}$. The uncertainty increased with the increase of the return period, implying significant uncertainty present in the extreme rainfall quantiles of the DDF curves. Also, the level of uncertainty at each station is different as there are different topography and characteristics at each particular location.

As shown in figure 7, the normal probability density functions of the DDF curves were plotted at $T=5$ and 20 yr to describe the uncertainty of the DDF curves. The results indicated that the uncertainty regarding the parameter estimation in the DDF curves owing to the sampling error can be considerable, especially for long return periods. These uncertainty ranges need to be addressed in any hydrological analysis and may have an adverse impact on the design of the hydraulic structures and decision-making for extreme hydrologic events if they are not seriously taken into consideration.

\section{Conclusions}

The quantification of uncertainty in DDF curves is crucial to investigate the implication of uncertainty on the performance reliability of the hydrologic risk analysis and design. This is especially important for a country like Malaysia where floods are considered the most devastating natural disaster. Thus, the DDF curves with quantified uncertainty bounds would help in the estimation of reliable rainfall DDF relationships and quantify the uncertainty associated with the flood risk assessment tasks.

This study presents the bootstrap procedure to evaluate the uncertainty features of DDF curves in the Kelantan river basin. The annual maximum rainfall series of durations between 24 and $120 \mathrm{~h}$ were derived from the stochastic rainfall model outputs. The bootstrap samples were fitted to the GEV distribution and the relevant parameters were determined through the L-moments approach. The
GEV parameters were modelled as a function of duration and these relations were used to establish the rainfall DDF curves. Finally, the uncertainty in DDF curves due to sampling variability is quantified in terms of $95 \%$ confidence intervals based on bootstrap resampling and the bootstrap distribution was represented by a normal distribution. The computation results showed that with the increase of the return period, the lower and upper bounds of the $95 \%$ confidence intervals were getting larger, which indicated that the uncertainty of the DDF curves was increasing. It was also shown that there was a significant uncertainty in the extreme rainfall quantile estimation due to the sampling of data. This implies that neglecting the uncertainty can result in great risks associated with the hydrological modelling and subsequent design decisions.

In summary, the proposed bootstrap procedure is effective, easy to implement and able to quantify the uncertainty in a statistic. It can be applied for other rainfall frequency analysis to derive the rainfall DDF relationships but the concluding remarks may not be applicable because the results may vary among different model structures. It should be noted that this study only considers the parameter uncertainty, which may not completely describe the uncertainty in a modelling process. In a thorough uncertainty analysis, a comprehensive assessment of various sources of uncertainty should be performed. Therefore, further investigations are needed to study other sources of uncertainty, such as the data uncertainty that includes measurement errors, the operational uncertainty caused by human factors that often are being neglected in a modelling procedure and the natural uncertainty due to the intrinsic randomness of the natural process.

\section{Acknowledgements}

The authors wish to express their appreciation to the Malaysian Meteorological Department (MMD) for providing the rainfall data and the Ministry of Education Malaysia (MOE) for the financial support.

\section{References}

Ariff N M, Jemain A A, Ibrahim K and Wan Zin W Z 2012 IDF relationships using bivariate copula for storm events in Peninsular Malaysia; J. Hydrol. 470-471 158-171. 
Borga M, Vezzani C and Fontana G D 2005 Regional rainfall depth-duration-frequency equations for an alpine region; Nat. Hazards 36 221-235.

Borujeni S C and Sulaiman W N A 2009 Development of Lmoment based models for extreme flood events; Malaysian J. Math. Sci. 3 281-296.

Brath A, Castellarin A and Montanari A 2003 Assessing the reliability of regional depth-duration-frequency equations for gaged and ungaged sites; Water Resour. Res. 39, https://doi.org/10.1029/2003WR002399.

Burn D H 2014 A framework for regional estimation of intensity-duration-frequency IDF curves; Hydrol. Process. 28 4209-4218.

Chang K B, Lai S H and Faridah O 2013 RainIDF automated derivation of rainfall intensity-duration-frequency relationship from annual maxima and partial duration series; J. Hydroinform. 15 1224-1233.

Chen J, Brissette F P and Leconte R 2010 A daily stochastic weather generator for preserving low-frequency of climate variability; J. Hydrol. 388 480-490.

Chen J, Brissette F P, Leconte R and Caron A 2012 A versatile weather generator for daily precipitation and temperature; Trans. ASABE 55 895-906.

Coles S, Pericchi L R and Sisson S 2003 A fully probabilistic approach to extreme rainfall modeling; J. Hydrol. 273 3550.

Dickey D A and Fuller W A 1979 Distribution of the estimators for autoregressive time series with a unit root; $J$. Am. Stat. Assoc. 74 427-431.

Fodor N, Dobi I, Mika J and Szeidl L 2010 MV-WG A new multi-variable weather generator; Meteorol. Atmos. Phys. 107 91-101.

Guhathakurta P, Sreejith O P and Menon P A 2011 Impact of climate change on extreme rainfall events and flood risk in India; J. Earth Syst. Sci. 120 359-373.

Haddad K, Rahman A and Green J 2010 Design rainfall estimation in Australia a case study using L moments and generalized least squares regression; Stoch. Environ. Res. Risk Assess. 25 815-825.

Hailegeorgis T T, Thorolfsson S T and Alfredsen K 2013 Regional frequency analysis of extreme precipitation with consideration of uncertainties to update IDF curves for the city of Trondheim; J. Hydrol. 498 305-318.

Hosking J R M 1990 L-Moments: Analysis and estimation of distributions using linear combinations of order statistics; J. R. Stat. Soc. B 52 105-124.

Hosking J R M and Wallis J R 1995 A comparison of unbiased and plotting-position estimators of L moments; Water Resour. Res. 31 2019-2025.

$\mathrm{Hu}$ Y-M, Liang Z-M, Liu Y-W, Zeng X-F and Wang D 2015 Uncertainty assessment of estimation of hydrological design values; Stoch. Environ. Res. Risk Assess. 29 501-511.

Jenkinson A F 1955 The frequency distribution of the annual maximum or minimum values of meteorological elements; Quart. J. Roy. Meteorol. Soc. 81 158-171.

Jiang P and Tung Y-K 2015 Incorporating daily rainfalls to derive rainfall DDF relationships at ungauged sites in Hong Kong and quantifying their uncertainty; Stoch. Environ. Res. Risk Assess. 29 45-62.

Kyselý J and Dubrovský M 2005 Simulation of extreme temperature events by a stochastic weather generator effects of interdiurnal and interannual variability reproduction; Int. J. Climatol. 25 251-269.

Landwehr J M, Matalas N C and Wallis J R 1979 Probability weighted moments compared with some traditional techniques in estimating Gumbel Parameters and quantiles; Water Resour. Res. 15 1055-1064.

Madsen H and Rosbjerg D 1997 Generalized least squares and empirical Bayes estimation in regional partial duration series index-flood modeling; Water Resour. Res. 33 771-781.

Madsen H, Mikkelsen P S, Rosbjerg D and Harremoës P 2002 Regional estimation of rainfall intensity-durationfrequency curves using generalized least squares regression of partial duration series statistics; Water Resour. Res. 38 21-1-21-11.

Malamud B D and Turcotte D L 2006 The applicability of power-law frequency statistics to floods; J. Hydrol. 322 $168-180$.

Mirzaei M, Huang Y F, Lee T S, El-Shafie A and Ghazali A H 2013 Quantifying uncertainties associated with depth duration frequency curves; Nat. Hazards 71 1227-1239.

Mirzaei M, Huang Y F, El-Shafie A, Chimeh T, Lee J, Vaizadeh N and Adamowski J 2015 Uncertainty analysis for extreme flood events in a semi-arid region; Nat. Hazards $\mathbf{7 8}$ 1947-1960.

Nadarajah S and Choi D 2007 Maximum daily rainfall in South Korea; J. Earth Syst. Sci. 116 311-320.

Ngongondo C S, Xu C Y, Tallaksen L M, Alemaw B and Chirwa T 2011 Regional frequency analysis of rainfall extremes in southern Malawi using the index rainfall and L-moments approaches; Stoch. Environ. Res. Risk Assess. 25 939-955.

Noguchi K, Gel Y R and Duguay C R 2011 Bootstrap-based tests for trends in hydrological time series, with application to ice phenology data; J. Hydrol. 410 150-161.

Overeem A, Buishand A and Holleman I 2008 Rainfall depth-duration-frequency curves and their uncertainties; J. Hydrol. 348 124-134.

Papalexiou S M and Koutsoyiannis D 2013 Battle of extreme value distributions: A global survey on extreme daily rainfall; Water Resour. Res. 49 187-201.

Prudhomme C, Jakob D and Svensson C 2003 Uncertainty and climate change impact on the flood regime of small UK catchments; J. Hydrol. 277 1-23.

Richardson C W 1981 Stochastic simulation of daily precipitation, temperature, and solar radiation; Water Resour. Res. 17 182-190.

Sarhadi A and Soulis E D 2017 Time-varying extreme rainfall intensity-duration-frequency curves in a changing climate; Geophys. Res. Lett., https://doi.org/10.1002/ 2016GL072201.

Semenov M A and Brooks R J 1999 Spatial interpolation of the LARS-WG stochastic weather generator in Great Britain; Clim. Res. 11 137-148.

Sisson S A, Pericchi L R and Coles S G 2006 A case for a reassessment of the risks of extreme hydrological hazards in the Caribbean; Stoch. Environ. Res. Risk Assess. 20 296-306.

Tiwari M K and Chatterjee C 2010 Development of an accurate and reliable hourly flood forecasting model using wavelet-bootstrap-ANN WBANN hybrid approach; $J$. Hydrol. 394 458-470. 
Win N L and Win K M 2014 The probability distributions of daily rainfall for kuantan river basin in Malaysia; Int. J. Sci. Res. 3 977-983.

Wotling G, Bouvier C, Danloux J and Fritsch J-M 2000 Regionalization of extreme precipitation distribution using the principal components of the topographical environment; J. Hydrol. 233 86-101.
Yin J, Yan D, Yang Z, Yuan Z, Yuan Y and Zhang C 2016 Projection of extreme precipitation in the context of climate change in Huang-Huai-Hai region, China; J. Earth Syst. Sci. 125 417-429.

Zalina M D, Desa M N M, Nguyen V-T-A and Kassim A H M 2002 Selecting a probability distribution for extreme rainfall series in Malaysia; Water. Sci. Technol. 45 63-68.

Corresponding editor: A K SAHAI 